\section{HUMANAS E SOCIAIS}

V.9 * N.2 • 2021 • Fluxo Contínuo

ISSN Digital: 2316-3801

ISSN Impresso: 2316-3348

DOI: 10.17564/2316-3801.2021v9n2p244-256
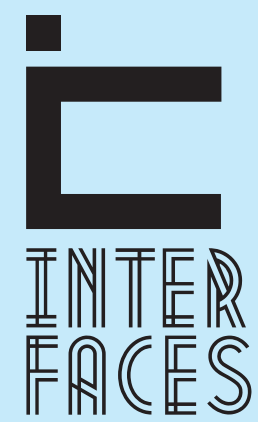

CIENTÍFICAS

\title{
ESTRATÉGIAS PARA RECEPÇÃOE MEDIAÇÃO DE JOVENS COM DEFICIÊNCIA INTELECTUAL NO MUSEU DA GEODIVERSIDADE [IGEO/UFRJ]
}

STRATEGIES FOR RECEIVING AND MEDIATING YOUNG PEOPLE WITH INTELLECTUAL DISABILITIES AT THE MUSEUM OF GEODIVERSITY [IGEO/UFR])

\section{ESTRATEGIAS PARA RECIBIR Y MEDIAR A LOS JÓVENES CON DISCAPACIDAD INTELECTUAL EN EL MUSEO DE GEODIVERSIDAD (IGEO/UFRJ)}

Damiane Daniel Silva Oliveira dos Santos ${ }^{1}$ Aline Rocha de Souza Ferreira de Castro ${ }^{2}$ Vera Lucia Vieira de Souza ${ }^{3}$ Miryam Bonadiu Pelosi ${ }^{4}$

\section{RESUMO}

O Museu da Geodiversidade (MGeo) é um museu universitário vinculado ao Instituto de Geociências (IGEO/UFRJ), localizado na Cidade Universitária, Ilha do Fundão, Rio de Janeiro. Por meio de uma parceria com o Departamento de Terapia Ocupacional e com o Curso de Especialização em Acessibilidade Cultural, ambos da UFRJ, o museu reuniu materiais e criou estratégias para a recepção e mediação de jovens com Deficiência Intelectual (DI). Trata-se de uma pesquisa descritiva que envolveu profissionais da Museologia, da Educação e da Terapia Ocupacional. 0 objetivo deste trabalho foi sistematizar as estratégias de acessibilidade adotadas pelo MGeo na recepção e mediação desse público alvo articuladas com o serviço de Terapia Ocupacional do Instituto de Puericultura e Pediatria Martagão Gesteira - IPPMG/UFRJ. Antes da visita, os jovens e familiares receberam informações sobre a exposição, como chegar ao local e foram apresentadas as estratégias pensadas pela equipe de acessibilidade do museu para favorecer a fruição do espaço cultural. 0 instrumento utilizado para a coleta de dados foi um formulário de registro da observação, apresentando perguntas estruturadas para uma observação não-participante das visitas mediadas. Os dados mostraram que, a partir da experiência com as visitas, foi possível reunir uma série de materiais adaptados para favorecer a participação e o engajamento dos jovens com DI. Conclui-se que o MGeo vem trabalhando para a eliminação da exclusão cultural, mas ainda existem desafios a serem superados. As estratégias analisadas e sistematizadas nesse estudo contribuirão para futuras mediações acessíveis para jovens com deficiência intelectual. 


\section{PALAVRAS-CHAVE}

Acessibilidade. Acessibilidade Cultural. Deficiência Intelectual. Terapia Ocupacional. Inclusão.

\section{ABSTRACT}

The Museum of Geodiversity (MGeo) is an university museum linked to the Geosciences Institute (IGEO/UFRJ), located in Cidade Universitária, Ilha do Fundão, Rio de Janeiro. Through a partnership with the Occupational Therapy Department and the Specialization Course in Cultural Accessibility, both from UFRJ, the museum gathered materials and created strategies for the reception and mediation of young people with intellectual disabilities (ID). It is a descriptive research that involved professionals from Museology, Education and Occupational Therapy. The objective of the work was to systematize as an accessibility objective adopted by MGeo in the reception and mediation of this target audience articulated with the Occupational Therapy service of the Institute of Childcare and Pediatrics Martagão Gesteira - IPPMG / UFRJ. Before the visit, the youngsters and the parents received information about the exhibition, how to get there and were configured as designed by the museum's accessibility team to favor the enjoyment of the cultural space. The instrument used for data collection was an observation registration form, presenting structured questions for a non-participant observation of a mediated visit. The available data that, from the experience with the visits, it was possible to gather a series of materials adapted to favor the participation and engagement of young people with ID. It is concluded that MGeo has been working to eliminate cultural exclusion, but there are still challenges to be overcome. The strategies analyzed and systematized in this study will contribute to future mediations obtained for young people with intellectual disabilities.

\section{KEYWORDS}

Accessibility. Cultural Accessibility. Intellectual Disability. Occupational Therapy. Inclusion.

\section{RESUMEN}

El Museo de Geodiversidad (MGeo) es un museo universitario vinculado al Instituto de Geociencias (IGEO / UFRJ), ubicado en Cidade Universitária, Ilha do Fundão, Río de Janeiro. A través de una asociación con el Departamento de Terapia Ocupacional y el Curso de Especialización en Accesibilidad Cultural, ambos de la UFRJ, el museo reunió materiales y creó estrategias para la recepción 
y mediación de jóvenes con Discapacidades Intelectuales (DI). Se trata de una investigación descriptiva que involucra tu profesión de Museología, Educación y Terapia Ocupacional. El objetivo de este trabajo fue sistematizar las estrategias de accesibilidad adoptadas por MGeo en la recepción y mediación de público articulado, como el servicio de Terapia Ocupacional del Instituto Martagão Gesteira de Puericultura e Pediatria - IPPMG / UFRJ. Antes de la visita, los jóvenes y sus familias recibirán información sobre la exposición, cómo conocer el lugar y cómo presentar las estrategias trazadas por el equipo de accesibilidad del museo para favorecer el disfrute del espacio cultural. El instrumento utilizado para la recolección de datos fue un formulario de registro de observación, que presenta preguntas estructuradas para la observación no participante de las visitas mediadas. Los datos mostrarán que, a partir de la experiencia con las visitas, será posible recopilar una serie de materiales adaptados para favorecer la participación de dos jóvenes con DI. Se concluye que MGeo está trabajando para eliminar la exclusión cultural, pero aún quedan desafíos por superar. A medida que se analizan y sistematizan, se considera que las estrategias contribuyen a futuras transferencias de mediaciones para jóvenes con discapacidad intelectual.

\section{PALABRAS CLAVE}

Accesibilidad. Accesibilidad cultural. Discapacidad intelectual. Inclusión. Terapia Ocupacional.

\section{INTRODUCÇÃO}

O Museu da Geodiversidade (MGeo) está vinculado ao Instituto de Geociências (IGEO) da Universidade Federal do Rio de Janeiro (UFRJ) e localiza-se na Cidade Universitária, Ilha do Fundão, Rio de Janeiro. A principal exposição do museu, denominada Memórias da Terra, foi inaugurada em setembro de 2011 e expõe um acervo composto de fósseis, minerais, rochas, meteoritos e reconstituições diversas para contar a história do Planeta Terra e dos seres vivos que nele habitaram ao longo do tempo.

Nos últimos anos a equipe do Museu da Geodiversidade vem se deparando com inúmeros desafios no campo da acessibilidade, como o de produzir material adaptado para a recepção do público com necessidades específicas, formar mediadores e aumentar a demanda por visitas de pessoas com deficiência ao museu, num processo de formação de público. Tais ações são motivadas para atender e garantir os direitos de acesso a bens culturais em formato acessível discriminado na Lei Brasileira de Inclusão da Pessoa com Deficiência (LBI) (BRASIL, 2015).

O conceito de Acessibilidade Cultural apresentado por Sarraf (2018, p. 25) destaca que os espaços culturais, públicos e privados "devem oferecer um conjunto de adequações, medidas e atitudes que proporcionem bem-estar, acolhimento e acesso à fruição cultural para pessoas com deficiência, beneficiando públicos diversos". Nesse sentido, os museus, para que sejam plenamente acessíveis, necessitam sensibilizar e capacitar seus funcionários, criar e adequar espaços, utilizar recursos, estratégias, 
serviços e produtos da área de Tecnologia Assistiva (TA), que promovam oportunidades equitativas para todos os públicos, independentemente da condição física, comunicacional e intelectual das pessoas.

Conforme pode ser observado nos dados disponíveis no Guia de Museus e Centros de Ciências Acessíveis da América Latina e do Caribe, as iniciativas de acessibilidade em museus de ciências estão cada vez mais presentes. 0 Guia, publicado em 2017, aborda aspectos relacionados à acessibilidade física, auditiva, visual e intelectual, sinalizando quais estratégias estão disponíveis para cada espaço (ROCHA et al., 2017).

Dentre os 22 espaços museais localizados no município do Rio de Janeiro, todos afirmaram possuir alguma estratégia, ação ou equipamento voltados para a acessibilidade física; 20 deles afirmaram o mesmo para a visual; 18 para a auditiva e apenas 2 para intelectual. Esses dados podem ter mudado de 2017 até a publicação deste trabalho, mas são importantes ao revelar que as estratégias voltadas para a acessibilidade física, visual e auditiva são as mais difundidas nesses espaços museais, no entanto, ainda pouco se fez em relação às adaptações que facilitem a fruição cultural de pessoas com deficiência Intelectual.

As pessoas com DI apresentam diferentes necessidades de apoio para o desempenho de suas atividades com autonomia e independência. Em ambientes culturais, significa que este público pode apresentar demandas específicas e que sua compreensão e capacidade não deve ser subestimada. Considerando a importância do tema para a área de acessibilidade cultural, o objetivo deste trabalho foi sistematizar as estratégias de acessibilidade adotadas para a recepção e mediação de jovens com Deficiência Intelectual na exposição Memórias da Terra do MGeo.

\section{MÉTODO}

Trata-se de uma pesquisa descritiva com abordagem qualitativa que envolveu profissionais da Museologia, da Educação e da Terapia Ocupacional (TO) da Universidade Federal do Rio de Janeiro (UFRJ). A pesquisa qualitativa "responde a questões muito particulares [] ou seja, trabalha com o universo de significados, motivos, aspirações, crenças, valores e atitudes” (MINAYO 2015, p. 21).

O objeto dessa pesquisa foi o Museu da Geodiversidade (IGEO/UFRJ) e as visitas foram articuladas pelo serviço de Terapia Ocupacional do Instituto de Puericultura e Pediatria Martagão Gesteira (IPPMG) da UFRJ. Antes de cada visita foi feito o planejamento junto com os responsáveis do MGeo, os jovens e familiares receberam informações sobre a exposição, orientação e apoio para a chegada ao local e foram apresentadas às estratégias pensadas pela equipe de acessibilidade do museu para favorecer a fruição do espaço cultural.

Foram realizadas três visitas ao museu, no período de 2013 a 2019. A primeira contou com a participação de 15 crianças e jovens e seus familiares; as demais contaram com 13 crianças e jovens com DI com idades entre 8 e 16 anos, e seus familiares.

Com exceção da primeira, na preparação para as visitas, a equipe do MGeo organizou o material produzido anteriormente pelo grupo com o objetivo de facilitar a participação dos jovens com defi- 
ciência intelectual e realizou uma conversa com os mediadores do Museu da Geodiversidade, explicando como deveriam proceder. Ao final das visitas foi feita a avaliação com os familiares e jovens participantes, equipe do MGeo, docentes e discentes do curso de Terapia Ocupacional.

Para sistematizar as observações sobre a mediação, na terceira visita foi elaborado um instrumento para registro, apresentando 17 perguntas estruturadas para uma observação não-participante, sobre a preparação para a visita, a realização da mediação, o uso de recursos, a linguagem estabelecida pelos mediadores, a estimulação de uma visita multissensorial, a interação dos jovens e a segurança do grupo no local. 0 mesmo foi respondido por uma pedagoga, uma museóloga e uma terapeuta ocupacional que acompanharam a visita.

\section{RESULTADOS}

O Museu da Geodiversidade passou a ter contato com jovens com deficiência intelectual a partir de uma parceria com o Departamento de Terapia Ocupacional da UFRJ, iniciada com a participação de uma das autoras, no Curso de Especialização em Acessibilidade Cultural da UFRJ. Em dezembro de 2013, a equipe do Museu recebeu a primeira visita de crianças e jovens atendidos pelo serviço de Terapia Ocupacional do Instituto de Puericultura e Pediatria Martagão Gesteira (IPPMG), acompanhadas de seus familiares, estagiários e docentes de Terapia Ocupacional. Para esta visita houve o contato inicial e uma visita preparatória de estudantes extensionistas de Terapia Ocupacional (SOUZA; PELOSI, 2011) com a museóloga do MGeo para identificar barreiras e posterior preparação de material de apoio para trabalhar os temas abordados na exposição e o transporte conjunto de todo o grupo para o deslocamento dentro do campus.

Nessa visita foram usadas miniaturas de dinossauros, pranchas de comunicação com imagens, representando o vocabulário correspondente ao conteúdo abordado na exposição do MGeo, cuidados com sons altos e outros símbolos como beber água, ir ao banheiro, comer e opinar sobre a visita. Não houve uma preparação específica dos mediadores, mas a avaliação foi bem positiva. Essa foi a primeira visita a um museu de todos os participantes.

Após essa primeira visita de crianças e jovens com alterações do desenvolvimento, incluindo DI, foi observada a necessidade de utilizar materiais concretos para estimular a participação dos visitantes durante a visita. Assim, foi montada uma caixa de recursos para apoiar as visitações desse público alvo. A caixa continha miniaturas do globo terrestre, jacarés, mamutes, dinossauros, sapos de pelúcia, lupas, lanternas, frascos com sal e cordões com um mineral.

A segunda visita foi organizada em dezembro de 2015, com a recepção de dois grupos de jovens com síndrome de Down, em dois turnos, com reunião prévia entre a equipe do Museu e docentes do Departamento de Terapia Ocupacional, envolvidos no Curso de Especialização em Acessibilidade Cultural e na assistência dos jovens com deficiência. 0 grupo totalizou 9 jovens e seus familiares. 0 material preparatório permaneceu disponível para dar suporte às visitas e atividades educativas.

Entre os itens produzidos encontram-se pranchas de comunicação com imagens das salas de exposição, vocabulário relacionado aos temas abordados (terra, vulcão, minerais, animais e vegetais, 
jogos adaptados para diferentes condições motoras, visuais e cognitivas e adaptação de material para atividade de colorir) (FERREIRA, 2016; GARCIA, 2016). Esse material foi elaborado por duas Terapeutas Ocupacionais, bolsistas do Curso de Especialização em Acessibilidade Cultural (UFRJ), que atuaram como residentes no MGeo de 2015 a 2016.

As pranchas de comunicação foram usadas antes, durante e depois da visita. Após a visita, enquanto os jovens realizavam jogos adaptados com a equipe do educativo, os familiares participaram de uma roda de conversa.

A terceira visita aconteceu em abril de 2019 por sugestão de um dos jovens que havia participado da segunda visita. $\mathrm{O}$ grupo de visitantes foi composto de quatro jovens com DI e quatro familiares. Apoiaram a visita três estudantes de Terapia Ocupacional, uma estagiária do serviço de Terapia Ocupacional do IPPMG e a supervisora do estágio. A mediação foi realizada por quatro pessoas, sendo dois servidores e dois bolsistas de extensão do MGeo, dos cursos de Geologia e Bacharelado em Ciências Matemática e da Terra. Com exceção desse jovem, os demais visitantes e seus familiares estavam tendo sua primeira experiência de visita a um museu.

Durante a segunda e terceira visita, foi possível observar que os mediadores iniciaram usando palavras pouco usuais para aquele público como "vou fazer uma pequena introdução", mas, aos poucos foram ajustando o vocabulário. Outro ponto observado foi a dificuldade de explicar os conceitos de modo que pudesse ser compreendido pelos jovens, como quem era Monteiro Lobato, personagem que recepciona os visitantes na entrada do MGeo.

Os mediadores anteciparam riscos e mudanças bruscas de ambiente como aquelas com sons fortes e permitiram a exploração das salas pelo tempo desejado pelo grupo, percebendo o envolvimento dos jovens. Em uma das salas, em que o ambiente era escuro, ofereceram objetos para os jovens segurarem, o que os auxiliou enfrentar a escuridão e realizar uma exploração atenta das peças expostas.

A terceira visita teve a duração de uma hora e quinze minutos. Após o término, o grupo foi convidado para participar das atividades educativas em uma sala anexa à exposição. Foram realizadas duas atividades com material adaptado com símbolos gráficos, fotografias e imagens, produzidos anteriormente.

A primeira atividade proposta consistiu na apresentação de perguntas relacionadas à exposição, com quatro alternativas de resposta e apenas uma correta. Essas perguntas e suas alternativas de resposta foram feitas em símbolos pictográficos e fotografias da própria exposição, com opções móveis, para que a resposta fosse fixada com velcro, na parte central da página, ou só apontada. As perguntas foram lidas pelos mediadores e os jovens apontaram para a resposta que consideraram correta, demonstrando compreensão do conteúdo perguntado.

A segunda atividade desenvolvida foi o jogo da memória, formado por peças emborrachadas, contendo imagens de dinossauros brasileiros. Os jovens realizaram a atividade adaptada com autonomia e apenas um deles precisou do auxílio.

Para avaliação da visita pelos jovens, foi utilizada a caixa de recursos com objetos relacionados à exposição. Essa caixa foi utilizada durante toda visita, como apoio ao trabalho e, ao final, o mediador pediu para que os jovens selecionassem o objeto que representava o que eles tinham mais gostado na visita. Eles escolheram o sapo, o dinossauro, a Terra e o jacaré. Com a prancha de comu- 
nicação das salas do Museu, os jovens indicaram que a sala Feras do Cretáceo, onde se encontram os dinossauros, foi a que eles mais gostaram de ver na exposição. Ao término, houve uma conversa com os familiares para avaliação da visita.

0 relato das famílias em todas as visitas foi de satisfação e acolhimento tanto no sentido de terem visto os filhos/netos interagindo, quanto de terem, também, aprendido e se divertido durante a visita.

Os familiares destacaram que os mediadores foram atenciosos e buscavam chamar os jovens para observarem o acervo da exposição ou até mesmo para ouvirem as explicações. Enfatizaram, também, que conseguiram empregar uma linguagem que faz parte do cotidiano dos visitantes, não usando apenas termos acadêmicos ou técnicos. Os acompanhantes procuraram intervir o mínimo possível durante a visita, deixando os mediadores a conduzirem. Um dos acompanhantes salientou a importância de outras pessoas saberem lidar com os jovens com deficiência.

A partir das observações realizadas nestas visitas foi possível organizar recomendações específicas para o Museu da Geodiversidade, mas que podem ser adaptadas para a realidade de outros museus que desejarem receber jovens com deficiência intelectual. As estratégias recomendadas foram organizadas em itens, para auxiliar a compreensão e a aplicação. São 10 recomendações ao todo que serão detalhadas a seguir.

1. Conversa inicial: utilizar pranchas de comunicação para antecipar o conteúdo que será visto na exposição, associando a algo do universo da população alvo;

2. Falar clara e descritivamente, evitando termos acadêmicos e, apoiando-se, sempre que necessário, em objetos, gestos e símbolos gráficos. Recepcionar e mediar para públicos diversificados exige dos educadores posicionamentos rápidos e ações criativas, de modo a estabelecer o diálogo;

3. Expressões como "Planeta Terra Primitivo" associar com "planeta bebê"; "meteorito" associar com "estrela cadente"; ao invés de falar "vou fazer uma pequena introdução", falar "vou começar"; assim como "pintura rupestre" para "desenhos na caverna"; "animais carnívoros e herbívoros" para "animais que comem carne e plantas" e "amonita" parece com um "caracol”.

4. É essencial evitar o uso de metáforas, de ideias difíceis de perceber ou conceitos muito abstratos e que exijam conhecimentos específicos de outras áreas. A explicação dos recursos e acervos que estão do circuito expositivo exige muitos conhecimentos geológicos e as explicações em torno dos processos e teorias, como por exemplo, explicar a teoria da Deriva Continental e das extinções em massa e assimilar conceitos como tempo profundo e bilhões de anos. Por isso, recomenda-se enfocar a explicação no objeto e, se necessário, recorrer a comparações com os materiais concretos que estão na caixa de recursos e/ou imagens claras e símbolos gráficos que compõem as pranchas de comunicação;

5. Durante a mediação devem-se evitar questões do tipo “alguém tem alguma pergunta?” Pois essa indagação, muitas vezes, fica sem resposta. Pode-se combinar inicialmente que, caso alguém tenha dúvida, pergunte ou levante o braço a qualquer momento;

6. Sempre antecipar um fato ou acontecimento ao grupo, a fim de se evitar surpresas e algum constrangimento por algo que já é conhecido no circuito expositivo como área sensível. A surpresa, no caso de jovens com DI, pode causar a desorganização e, consequentemente, a interrupção da mediação;

7. Ao se lidar com um grupo com DI, deve-se pensar em diversas estratégias que orientem sobre o quê e como fazer. Mas, primeiramente, deve-se optar por dar-lhes a devida atenção e demonstrar 
interesse por sua comunicação, pois escutá-los, ainda que não seja de modo verbal, é a melhor forma de sentir a sua expressão. Dessa forma, todas as curiosidades referentes à temática serão atendidas, por meio de respostas às suas indagações;

8. É importante identificar um momento e local para descanso. Na exposição atual, a escolha é o módulo "E a vida conquista os continentes" por terem peças para serem observadas no alto. Nesta sala é conveniente o mediador convidar o grupo a se sentar no chão como medida para aumentar a concentração, descansar e facilitar a observação do fóssil do animal que se encontra pendurado no teto da sala. Com a utilização da percepção visual, o mediador pode iniciar a caracterização com as seguintes indagações: que bicho vocês acham que é? Parece com o quê? Vamos pegar na caixa de recursos o brinquedo que vocês acham que pode ser esse animal em cima de nós? A partir dessas indagações, pode-se explicar realmente o que o item apreciado representa ampliando, desse modo, o entendimento. As opções também podem estar em cartões ou em uma prancha de comunicação;

9. Com relação à segurança do grupo de jovens com DI, é essencial mantê-lo sempre junto, pois facilita o controle por parte dos responsáveis. Da mesma forma, torna-se válido solicitar ao porteiro que caso alguém saia sozinho do museu, durante a mediação, alerte imediatamente a equipe. Outros perigos devem ainda ser informados a todos os visitantes, tais como: os degraus e rampas em algumas salas, as plantas que podem machucar, escuridão de algumas salas e o risco de debruçar sobre as cúpulas de vidro;

10. É preciso sempre respeitar o ritmo dos jovens. Caso necessário, personalizar a visita comum a um atendimento mais individualizado, mas sempre procurando levar as indagações para o coletivo para que se aguce a curiosidade de todos e se construa uma aprendizagem significativa.

\section{DISCUSSÃO}

As estratégias usadas pelo MGeo se mostraram úteis para a minimização das barreiras existentes e atração de um público até então excluído. Na mediação e no museu foram incorporados elementos da área de Tecnologia Assistiva (TA), área de conhecimento definida na LBI como "produtos, equipamentos, dispositivos, recursos, metodologias, estratégias, práticas e serviços que objetivem promover a funcionalidade, relacionada à atividade e à participação da pessoa com deficiência ou com mobilidade reduzida" (BRASIL, 2015, on-line).

A TA se aplica a diversas áreas entre as quais estão a comunicação e a adaptação de jogos, envolvidas no presente trabalho.

Para favorecer o entendimento e a expressão foram usados recursos de Comunicação Alternativa e Ampliada (CAA), área da TA voltada para oferecer alternativas para pessoas com dificuldades comunicativas, ou seja, pessoas que não podem ser expressar pela fala e/ou escrita de forma funcional. As pranchas de comunicação podem ser elaboradas com miniaturas, fotografias, figuras, símbolos gráficos, letras ou palavras correspondentes ao vocabulário necessário para expressão de desejos, necessidades e opinião (BEUKELMAN; MIRENDA, 2005), e ampliam a comunicação pelo uso de expressões faciais e gestos. 
Pessoas com deficiência intelectual podem apresentar dificuldades comunicativas, como alguns dos jovens que não falavam ou falavam com dificuldade. Além de permitir a expressão, o uso da CAA facilita a compreensão (von TETZCHNER, 2009), fator essencial para promover a acessibilidade de pessoas com DI, contribuindo para a formação de conceitos e envolvimento nas atividades apresentadas.

As pranchas de comunicação foram usadas na preparação da visita, motivando os visitantes; na conversa durante a visita quando necessário e na avaliação ao final. A CAA foi essencial para auxiliar na comunicação dos mediadores com os jovens, pois continha informações com símbolos e fotografias da exposição e permitiu a participação e o diálogo nas atividades realizadas ao final da visita. 0 item que desejavam comunicar era selecionado, apontando ou olhando, e o interlocutor respondia a sua sinalização, apontando e/ou verbalizando, estabelecendo, assim, o diálogo.

A mediação, ao possibilitar a participação das pessoas com deficiência, é um serviço de TA, pois só a disponibilidade de recursos não é suficiente para a fruição da exposição.

Outros recursos de CAA que podem contribuir com a fruição nos espaços culturais são textos em linguagem simples, apoiado com símbolos e objetos concretos relacionados à exposição que podem ser utilizados como elementos de apoio à visita mediada ou como recurso de avaliação da exposição pelos participantes com deficiência intelectual associada a dificuldades comunicativas. Os textos, assim como as pranchas de comunicação, podem ser impressos ou disponibilizados em tablets.

A linguagem simples é, também, uma estratégia imprescindível para a percepção do conteúdo pelas jovens com DI e deve ser usada na interação durante a visita bem como na produção de textos para divulgação e apresentação do conteúdo. 0 uso da linguagem simples não significa resumir nem minimizar as informações, mas falar de forma objetiva, direta, com palavras usuais e com linguagem visual (MASCARENHAS, 2018).

No início das visitas, os mediadores utilizaram um vocabulário mais rebuscado ou acadêmico. Porém, com o desenrolar da visita, eles adequarem o vocabulário à linguagem do público-alvo. Talvez esse fator tenha influenciado a percepção dos familiares que consideraram a linguagem dos mediadores adequada durante a visita. Desse modo, observou-se a importância da sensibilidade, por parte dos explanadores, no tocante ao entendimento e à compreensão dos visitantes. Como afirma Dias (2007), a aprendizagem ocorre a partir do concreto, em função das dificuldades do desenvolvimento da abstração que pessoas com DI apresentam. Por isso, o mediador deve fazer sempre uso de situações e exemplos concretos, evitando assim abstrações.

Nesse sentido, a caixa de recursos com objetos e miniaturas mostrou-se uma ferramenta indispensável para uma mediação acessível. Ela deve conter materiais selecionados, tendo como base o acervo da exposição, facilitando a compreensão do conteúdo apresentado. Em virtude de ter-se observado a necessidade de incentivar a investigação e de inserir os visitantes ativamente no processo de descobertas, a inclusão de lanternas e lupas nesta caixa foi uma estratégia apropriada e ajudou a superar o medo, a manter a atenção e a explorar o espaço e os detalhes de algumas peças com autonomia.

A parceria com terapeutas ocupacionais junto à equipe do museu possibilitou a incorporação de recursos de TA-CAA, adaptações de jogos e uso de estratégias que promoveram "oportunidades equitativas para todos os públicos, independentemente da condição física, comunicacional e intelectu- 
al das pessoas", como salienta Sarraf (2018, p. 25). As estratégias adotadas foram motivadoras do envolvimento e participação dos jovens com deficiência intelectual e seus familiares. A TA, CAA e adaptação de jogos são amplamente utilizadas na intervenção terapêutica e educacional das pessoas com deficiência (PELOSI, 2005), e puderam ser incorporadas no contexto da acessibilidade cultural.

Em todas as visitas houve um preparo do grupo dos visitantes como parte do atendimento de Terapia Ocupacional, mas os recursos utilizados foram estruturados de acordo com as demandas de cada grupo.

Desde a primeira visita vários formatos foram sendo testados. Na primeira visita, os terapeutas ocupacionais levaram miniaturas de dinossauros, o que facilitou a participação de alguns visitantes. A incorporação de materiais concretos na mediação do museu, feita com a montagem da caixa de recursos, mostrou-se de grande relevância e esses objetos foram incorporados à mediação. Em todas as visitas houve pelo menos um participante com medo da sala escura, o que na primeira visita foi contornado pela terapeuta ocupacional e, nas outras, pelos mediadores com o uso da lanterna como recurso.

Observamos ainda, na primeira visita, que os jovens ficaram um pouco cansados e mais dispersos, por isso, foi necessário estabelecer um local de pausa para descanso antes de dar continuidade à mediação.

A capacitação dos mediadores ocorre no início de cada semestre e inclui o uso dos recursos disponíveis e estratégias apresentadas, porém foi evidenciada a necessidade de aprimoramento desta capacitação para a interação e para uso dos recursos de tecnologia assistiva, em especial de comunicação alternativa durante a visita.

Sarraf (2015) salienta que as estratégias de comunicação sensorial e desenvolvimento de recursos de acessibilidade para pessoas com deficiência atraem e fidelizam este público. Ressalta-se que nas visitas relatadas tanto os jovens como seus familiares entraram pela primeira vez em um museu e manifestaram o desejo de voltar.

A interação multissensorial com a exposição e com as ações educativas permitem a todos os visitantes que utilizem suas diferentes percepções para fruir das manifestações culturais (SARRAF, 2018). Neste princípio, os mediadores incentivaram os jovens a fazerem uso de diferentes sentidos além da visão e da audição, ao estimularem o tato com os objetos de apoio e o toque nas peças da exposição e o paladar com a experimentação do sal que estava disponível na caixa de objetos, utilizando uma mediação multissensorial.

De forma gradativa, o grupo foi se envolvendo com as experiências vivenciadas, o que proporcionou um elevado interesse pela exposição. 0 acervo do MGeo disponível ao toque enaltece a acessibilidade, pois possibilita a concretização do conteúdo por parte dos visitantes, sobretudo daqueles com deficiência intelectual, além de tornar a fruição cultural dinâmica.

A parceria com a TO foi ainda uma estratégia de trazer o público com deficiência ao museu. Ainda é necessário formar esse público e divulgar as ações a ele dirigidas. 0 museu deve ser um espaço para todos e as pessoas com DI devem se sentir acolhidas e pertencentes a este espaço. A participação e avaliação dos familiares é um aspecto valoroso no desenvolvimento de estratégias acessíveis.

Um fator importante na acolhida de pessoas com DI é a relação do quantitativo de mediador-visitante. Em mediações, envolvendo pessoas com DI é comum o atendimento ser quase exclusivo, por isso a importância de grupos pequenos e de se possuir uma equipe interdisciplinar. 
A mediação precisa ser como uma contação de história, ou seja, envolvente, encantadora e estimuladora, além de ser realizada de uma forma diferenciada, dinâmica, interativa e alternativa. É viável que a equipe do museu faça da visita um encontro significativo e agradável, criando um ambiente propício para a socialização ao observar as características individuais e ao incentivar as iniciativas e o relacionamento com o grupo. Nossa sociedade apresenta diferentes indivíduos com diversas formas de pensar, de ver o mundo e de se colocar nele e neles estão incluídas as pessoas com DI. Oferecer um museu acessível é valorizar todas as pessoas, com ou sem deficiência, criança ou adulto, nacional ou estrangeiro.

\section{CONSIDERAÇÕES FINAIS}

Os dados mostraram que a equipe do MGeo, a partir da experiência com as visitas aqui relatadas, reuniu uma série de materiais adaptados para favorecer a participação e o engajamento dos jovens com DI na visita e nas atividades propostas pelo museu. O MGeo vem trabalhando para a eliminação da exclusão cultural, mas ainda existem desafios a serem superados. Espera-se que as estratégias analisadas e sistematizadas nesse estudo contribuam para futuras mediações acessíveis para jovens com deficiência intelectual.

\section{REFERÊNCIAS}

AAIDD. Definição de deficiência intelectual. s/d. Disponível em: https://www.aaidd.org/. Acesso em 30 jul. 2020.

BEUKELMAN, D. R.; MIRENDA, P. Augmentative and alternative communication: suporting children and adults with complex communication needs. 3. ed. EUA: Paul Brokes Publishing Co., 2005.

BRASIL. Lei nº 13.146, de 6 de julho de 2015. Lei Brasileira de Inclusão da Pessoa com Deficiência (Estatuto da Pessoa com Deficiência). Disponível em: http://www.planalto.gov.br/ccivil_03/_ ato2015-2018/2015/lei/l13146.htm. Acesso em: 30 jul. 2020.

DIAS, C. Construindo o caminho um desafio aos limites da Síndrome de Down. Disponível em: encurtador.com.br/vzDT2. Acesso em: 29 jul. 2020.

DINIZ, D. 0 que é deficiência. São Paulo: Editora Brasiliense. 2007. Coleção Primeiros Passos.

FERREIRA, M. de S. M. As possibilidades de atuação do terapeuta ocupacional na residência cultural. 2016. Monografia (em Acessibilidade Cultural) - Faculdade de Medicina, Universidade Federal do Rio de Janeiro, Rio de Janeiro, 2016. 
GARCIA, F. da S. F. As contribuições da terapia ocupacional no âmbito cultural: tornando o Museu acessível. 2016. 75 f. Trabalho de Conclusão de Curso (Especialização) - Faculdade de Medicina, Universidade Federal do Rio de Janeiro, Rio de Janeiro, 2016.

MASCARENHAS, D. F. P. A linguagem simples como acessibilidade para pessoas com deficiência intelectual na experiência do Cosmos no Museu do Amanhã. 2018. 115 f. Dissertação (Mestrado Profissional em Diversidade e Inclusão) - Universidade Federal Fluminense, 2018.

MINAYO, M. Pesquisa social: teoria, método e criatividade. 34. ed. Rio de Janeiro: Editora Vozes, 2015.

PELOSI, M. B. O papel do terapeuta ocupacional na tecnologia assistiva. Cadernos de Terapia Ocupacional da UFScar, v. 13, n. 1, 2005.

ROCHA, J. N.; MASSARANI, L.; GONÇALVES, J.; FERREIRA, F. B.; DE ABREU, W. V.; MOLENZANI, A. O.; INACIO, L. G. B. (org.). Guia de museus e centros de ciências acessíveis da América Latina e do Caribe. Rio de Janeiro: Museu da Vida; Casa de Oswaldo Cruz; Fiocruz: RedPOP; Montevidéu: Unesco, 2017.

SARRAF, V. P. Acessibilidade cultural para pessoas com deficiência: benefícios para todos. Revista do Centro de Pesquisa e Formação, n. 6, jun. 2018.

SARRAF, V. P. Acessibilidade em espaços culturais: mediação e comunicação sensorial. São Paulo: EDUC; FAPESP, 2015. 236 p.

SASSAKI, R. K. Atualizações semânticas na inclusão de pessoas: Deficiência mental ou intelectual? Doença ou transtorno mental? Revista Nacional de Reabilitação, ano IX, n. 43, p.9-10, mar./abr. 2005. Disponível em: http://www.pcd.mppr.mp.br/arquivos/File/ Artigo_Deficiencia_mental_ou_ intelectual.pdf. Acesso em: 21 jul. 2020.

SASSAKI, R. K. Inclusão: construindo uma sociedade para todos. 8. ed. Rio de Janeiro: WVA, 2010.

SOUZA, V. L. V.; PELOSI, M. B. Comunicação alternativa e a parceria do Curso de terapia

ocupacional com o ARASAAC. 2011. Disponível em: https://sites.google.com/site/ tecnologiaassistivaufrj/projeto-arasaac. Acesso em: 28 jul. 2020.

von TETZCHNER, S. Suporte ao desenvolvimento da comunicação suplementar e alternativa. In: DELIBERATO, D.; GONÇALVES, M. J.; MACEDO, E. C. Comunicação alternativa: teoria, prática, tecnologias e pesquisa. São Paulo: Memnon Edições Científicas, 2009. 
1 Especialista em Acessibilidade Cultural pela UFRJ e em Psicopedagogia Institucional pela Universidade Cândido Mendes; Pedagoga pela Universidade Estadual do Rio de Janeiro - UFRJ; Mestranda em Tecnologia Social pelo Núcleo Interdisciplinar em Desenvolvimento Social - UFRJ; Diretora Adjunta de Extensão do Instituto de Geociências da Universidade Federal do Rio de Janeiro - UFRJ.

E-mail: damiane@igeo.ufrj.br (21)981936175.

2 Doutora em Geologia - UFRJ; Mestra em Museologia e Patrimônio - UNIRIO/MAST; Especialista em Acessibilidade Cultural - UFRJ; Museóloga e vice-diretora do Museu da Geodiversidade. E-mail: alinecastro@igeo.ufrj.br (21) 3938-9461.

3 Doutora e Mestra em Educação - UERJ; Especialista em Acessibilidade Cultural; Professora Adjunta do Departamento de Terapia Ocupacional - DTO/ FM/ CCS - Universidade Federal do Rio de Janeiro - UFRJ; Professora do Curso de Especialização em Acessibilidade Cultural - DTO/FM/CCS/ UFRJ. E-mail: veravieirasouza@medicina.ufrj.br (21) 39386506.

4 Doutora e Mestra em Educação - UERJ; Professora Associada do Departamento de Terapia Ocupacional - DTO/ FM/ CCS - Universidade Federal do Rio de Janeiro e do Curso de Especialização em Acessibilidade Cultural - DTO/ FM/CCS/UFRJ - UFRJ. E-mail: miryampelosi@ufrj.br



A autenticidade desse artigo pode ser conferida no site https://periodicos. set.edu.br

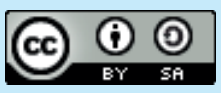

Este artigo é licenciado na modalidade acesso abertosob a Atribuição-Compartilhalgual CC BY-SA
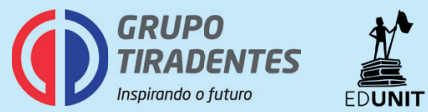